\title{
Nilutamide pneumonitis: a report on eight patients
}

Pierre Pfitzenmeyer, Pascal Foucher, Françoise Piard, Bruno Coudert, Marie Laure Braud, Patricia Gabez, Serge Lacroix, Jean-Pierre Mabille, Philippe Camus

\begin{abstract}
Background Nilutamide is a new, specific synthetic antiandrogen, released in several countries for the treatment of metastatic carcinoma of the prostate. Eight patients at the University Medical Centre at Dijon and affiliated referring hospitals developed reversible pulmonary opacities and respiratory symptoms while taking the drug.

Methods Records of eight patients who developed new, otherwise unexplained chest opacities while taking nilutamide were reviewed. In each patient a careful aetiological search was made for other environmental or endogenous causes. Six patients underwent bronchoalveolar lavage, and lavage fluid was cultured. Corticosteroids were not given, unless gas exchange was compromised (two patients).
\end{abstract}

Results The eight patients (all male) had had carcinoma of the prostate diagnosed on average 10.2 months earlier. All had improved with nilutamide, with a dramatic decrease of prostate specific antigen levels. Seven had reeeived nilutamide at the recommended dosage of $150 \mathrm{mg} / \mathrm{day}$, and one had received twice that amount. Treatment had lasted on average 113 (range 10-225) days, and the mean cumulated exposure was $21 \cdot 8$ (3-38) grams. The chest radiographs showed bilateral infiltrates, with no consistent topographic predilection. A restrictive lung defect was present in six patients and hypoxia in all (mean arterial oxygen tension $\left.\left(\mathrm{PaO}_{2}\right) 6.6 \mathrm{kPa}\right)$. Bronchoalveolar lavage showed lymphocytosis in four patients and neutrophilia in two. The outcome was favourable in all patients after they had stopped nilutamide only (five patients), with corticosteroids (two patients) or a simple reduction of nilutamide from 300 to 150 mg/day (one patient). Recovery was associated with improvement of pulmonary function and $\mathbf{P a O}_{2}$.

Conclusion Nilutamide is associated with interstitial pneumonitis in about $1 \%$ of patients and appears reversible.

Nilutamide (Anandron, fig 1) is a nitroaromatic non-steroidal antiandrogen, which bears a nitro moiety like nitrofurantoin, a well established lung toxin. The drug was launched in France in 1987, and subsequently in Belgium, Canada, The Netherlands, Portugal, and Sweden for the treatment of patients with metastatic carcinoma of the prostate. ${ }^{1}$ Although clinical studies have indicated that nilutamide is beneficial, some series, ${ }^{1}$ but not all, ${ }^{2}$ have shown that episodes of reversible pneumonitis may develop in patients receiving the drug. Three cases of nilutamide pneumonitis have been published in detail in pulmonary journals ${ }^{3-5}$ and two cases are briefly mentioned in a urological report $^{1}$; but the manufacturer's records indicate that about $1 \%$ of patients will develop a pulmonary reaction to the drug (Mery, Roussel Uclaf Paris, personal communication, 1992). Eight patients who developed reversible pneumonitis while receiving nilutamide for the treatment of prostatic carcinoma form the basis of this report.

\section{Methods}

The diagnosis of interstitial pneumonitis was established on the basis of the combination of dyspnoea of recent onset, evidence of new opacities on chest radiographs, and an abnormal pattern of cell populations in bronchoalveolar lavage fluid. Confirmation from transbronchial lung biopsy was obtained in two cases. Pulmonary function tests were performed with a portable Minato spirometer (distributed by Mediprom, Paris). The normal values used were those of Quanjer ${ }^{6}$ and Miller et al. $^{7}$ Bronchoalveolar lavage was performed according to established guidelines, ${ }^{8}$ with 150 $\mathrm{ml}$ of normal saline $(50 \mathrm{ml}$ in patient 8 , who tolerated the procedure poorly) instilled in the right middle lobe. Processing of lavage fluid included a cytospin preparation, followed by May-Grünwald-Giemsa staining. Cell counts were performed on 300 cells. Normal values

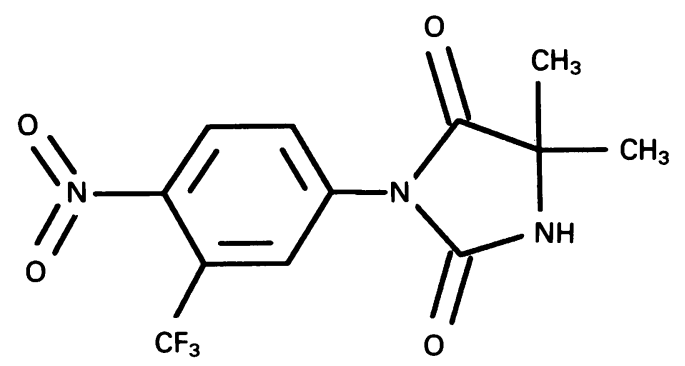

Figure 1 Chemical structure of nilutamide (RU-23908), a nitroaromatic compound. 
Table 1 Characteristics of patients with nilutamide pneumonitis

\begin{tabular}{|c|c|c|c|c|c|c|c|c|c|}
\hline $\begin{array}{l}\text { Patient } \\
\text { No }\end{array}$ & $\begin{array}{l}\text { Age } \\
(y)\end{array}$ & $\begin{array}{l}\text { Treatment } \\
\text { duration } \\
\text { (days) }\end{array}$ & $\begin{array}{l}\text { Total } \\
\text { dose }(g)\end{array}$ & Symptoms & $\begin{array}{l}\mathrm{PaO}_{2} \\
(\mathrm{kPa})\end{array}$ & $\begin{array}{l}V C \\
(\% \text { pred })\end{array}$ & $\begin{array}{l}\text { TLCO } \\
\text { (\% pred) }\end{array}$ & $\begin{array}{l}\text { Time to } \\
\text { recovery } \\
\text { (months) }\end{array}$ & $\begin{array}{l}V C \text { after } \\
\text { recovery } \\
\text { (\% pred) }\end{array}$ \\
\hline 1 & 73 & 10 & $3 \cdot 0$ & $\mathrm{D}, \mathrm{C}, \mathrm{F}$ & $4 \cdot 7$ & 65 & 50 & 1 & 80 \\
\hline 2 & 69 & 215 & $36 \cdot 5$ & None & $8 \cdot 8$ & 80 & 75 & 4 & 104 \\
\hline 3 & 67 & 225 & $38 \cdot 0$ & $\mathrm{D}, \mathrm{F}$ & 4.9 & 64 & 51 & 1 & 99 \\
\hline 4 & 89 & 82 & $12 \cdot 3$ & $\mathrm{D}, \mathrm{F}$ & $5 \cdot 2$ & 60 & ND & 6 & 72 \\
\hline 5 & 61 & 90 & $27 \cdot 0$ & $\mathrm{D}, \mathrm{WL}$, rash & $7 \cdot 1$ & 59 & 70 & $12^{\star}$ & 95 \\
\hline 6 & 80 & 76 & $15 \cdot 6$ & $\mathrm{D}, \mathrm{C}, \mathrm{F}$ & 6.5 & 110 & 71 & 2 & 110 \\
\hline 7 & 71 & 78 & $19 \cdot 2$ & D & $7 \cdot 5$ & 95 & ND & 1.5 & 93 \\
\hline 8 & 72 & 128 & $23 \cdot 1$ & $\mathrm{D}, \mathrm{F}$ & $8 \cdot 2$ & 55 & ND & 1 & 92 \\
\hline
\end{tabular}

${ }^{\star}$ Recovered despite continuing with nilutamide (at a lower dosage, $150 \mathrm{mg}$ instead of $300 \mathrm{mg}$ ).

$\mathrm{D}-$ dyspnoea; $\mathrm{C}-$ cough; $\mathrm{F}$-fever; WL-weight loss; $\mathrm{PaO}_{2}$ - arterial oxygen tension; VC-vital capacity; TLco-carbon monoxide transfer factor; ND-not done.

were taken from Laviolette. ${ }^{8}$ In some patients phenotypic expression of lymphocyte surface markers was studied by flow cytometry (FAC Scan, Becton Dickinson, Mountain View, California) with monoclonal antibodies (CD4: Ortho Diagnostic, Raritan, New Jersey; CD8: Dr A Bernard, Laboratoire d'Immunologie, Nice). Inhibition of leucocyte migration in the presence of the patient's serum and varying concentrations of pure nilutamide $(25,50$, and $100 \mu \mathrm{g} / \mathrm{ml}$ ) was examined. An index of migration lower than $75 \%$ (normal $100 \%$ ) was considered to be a positive result, as proposed by Akoun et al. ${ }^{5}$

\section{Clinical characteristics}

The clinical details of the eight men with nilutamide pneumonitis are presented in table 1. Their mean age was $72 \cdot 8$ (SE 6.0) years. Patients 2 and 5 were current smokers, whereas patient 3 had given up one year earlier. Patients 1 and 2 had previously been exposed to asbestos, and patient 1 had pleural plaques and mild asbestosis. Three patients $(2,3$, and 4$)$ had angina pectoris, and one of them (patient 4 ) had had a myocardial infarction nine years earlier. Patient 8 had undergone replacement of the aortic valve for atherosclerotic stenosis 21 months before diagnosis of prostatic carcinoma. None of these four patients with cardiac

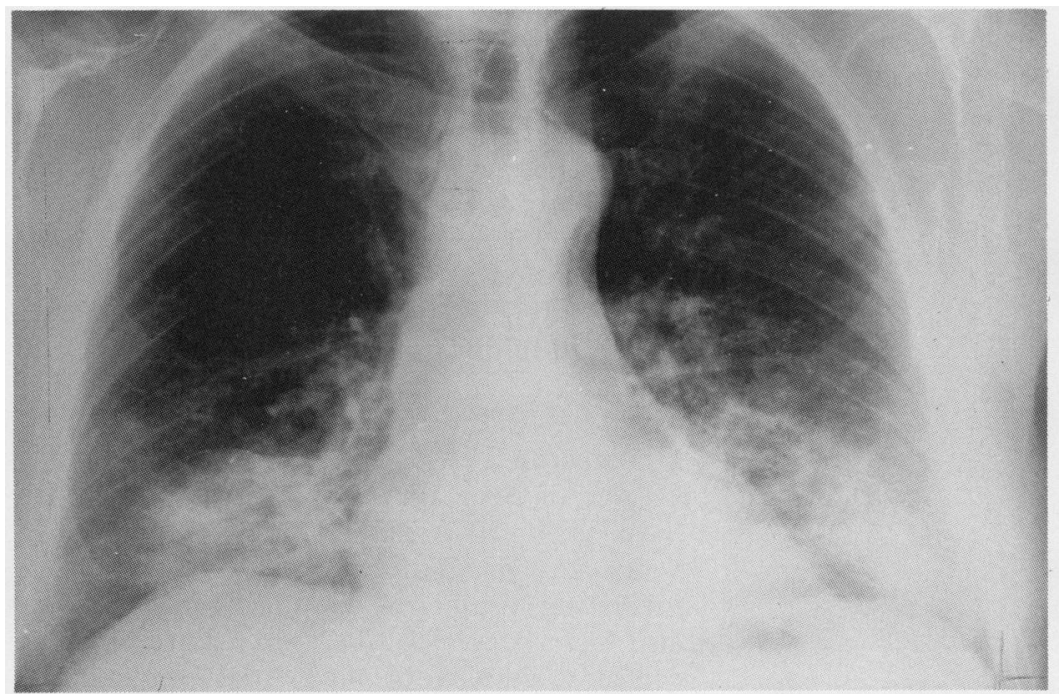

Figure 2 Bibasilar symmetrical infiltrates in nilutamide pneumonitis (patient 5). problems had ever presented clinically with overt left ventricular dysfunction, and none was taking amiodarone.

Adenocarcinoma of the prostate was found in each case-by transrectal biopsy in five cases, transurethral resection in two, and prostatectomy in one case. Bone metastases were identified by technetium- $99 \mathrm{~m}$ bone scintigraphy in six patients (cases 1, 2, 3, and 5-7). Locoregional spread was noted in patient 1 by ultrasonography and computed tomography, and preoperatively in patient 8 . Treatment of the carcinoma of the prostate included orchidectomy in four cases (patients 3, 5, 6, and 8), and in five cases $(1,2,3,6$, and 7$)$ a luteinising hormone releasing hormone analogue (triptoreline (Décapeptyl); Ipsen Laboratories, Paris) was given intramuscularly once a month.

Baseline pretreatment chest radiographs showed mild asbestosis in patient 1 . Patient 7 presented initially with enlarged left mediastinal lymph nodes, which were considered metastatic as their size decreased considerably after treatment with nilutamide. All other patients had a normal chest radiograph before treatment with nilutamide.

The duration of treatment with nilutamide averaged 113 (range 10-225) days. Six patients (cases $1,2,3$, and 6-8) had been given the recommended dosage of $300 \mathrm{mg} /$ day for four weeks, followed by $150 \mathrm{mg} /$ day. Patient $4 \mathrm{had}$ received $150 \mathrm{mg} /$ day from the beginning, whereas patient 5 had been given $300 \mathrm{mg}$ /day continously. The cumulated exposure averaged $21 \cdot 8$ (SE 9.6, range 3-38) g-see table 1.

A review of all drugs taken concomitantly showed that patient 3 was taking the $\beta$ blocker pindolol (15 mg/day for the past three years). Patient 8 was receiving flecainide $(200 \mathrm{mg} /$ day for the past year) because of supraventricular arrhythmia, and enalapril for hypertension (20 $\mathrm{mg} /$ day for the past two years). These drugs were continued with the same schedule after the episode of nilutamide pneumonitis, without any adverse effects.

Dyspnoea was present in seven cases (patients 1 and 3-8). Fever $\left(38 \cdot 0-39 \cdot 5^{\circ} \mathrm{C}\right)$ was present in five patients (Nos $1,3,4,6,8)$ and a non-productive cough in two (Nos 1 and 6). The interval between the onset of respiratory symptoms and the suspicion of drug induced pneumonitis averaged 27 (range 7-90) days. One patient (No 2) was symptom free, and interstitial pneumonitis was detected on a 
Figure 3 Biapical pulmonary infiltrates in nilutamide pneumonitis (patient 8).

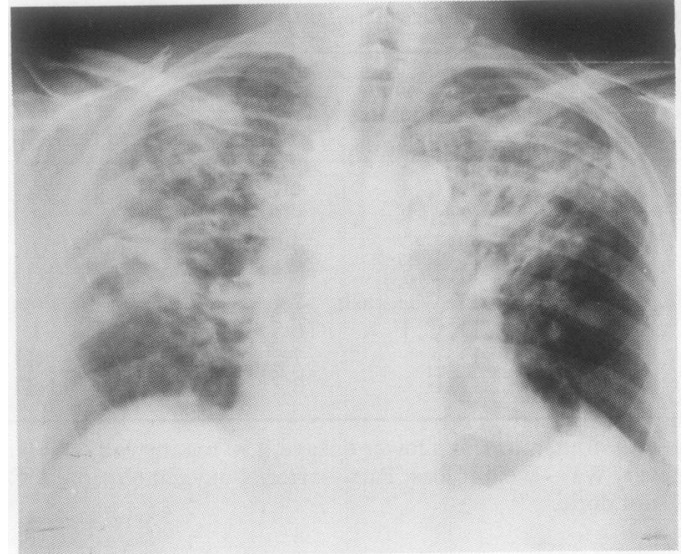

routine chest radiograph. Crackles were present in three patients, whereas auscultation indicated nothing abnormal in five cases.

The chest radiograph was abnormal in all patients. Bilateral infiltrates were present in four cases (patients 1, 2, 5, and 8). Bibasilar predominance was seen in two of these (patients 1 and 5: fig 2), whereas upper lobe predominance was seen in the two others (patients 2 and 8: fig 3). The four remaining patients (patients $3,4,6$, and 7 ) had diffuse bilateral infiltrates. Radiographic density ranged from minimal (patients 6 and 7) to pronounced (patients 3, 4, and 8). The computed tomogram displayed a variable pattern, including diffuse fluffy shadows (fig 4), localised consolidation, and diffuse haze with a ground glass appearance.

Pulmonary function tests showed a restrictive defect in six cases. These and other details are summarised in table 1.

One patient (No 5) had mildly increased $\gamma$ glutamyl transpeptidase activity $(85$ (normal <30) $\mathrm{kIU} / \mathrm{l}$ ) and aspartate aminotransferase (55 (normal 10-40) kIU/1), as already seen in some patients taking nilutamide. ${ }^{2}$ Patient 8 had transiently increased eosinophils $(21 \%$, total white cell count $\left.6.5 \times 10^{9} / 1\right)$ and raised $\mathrm{IgE}$

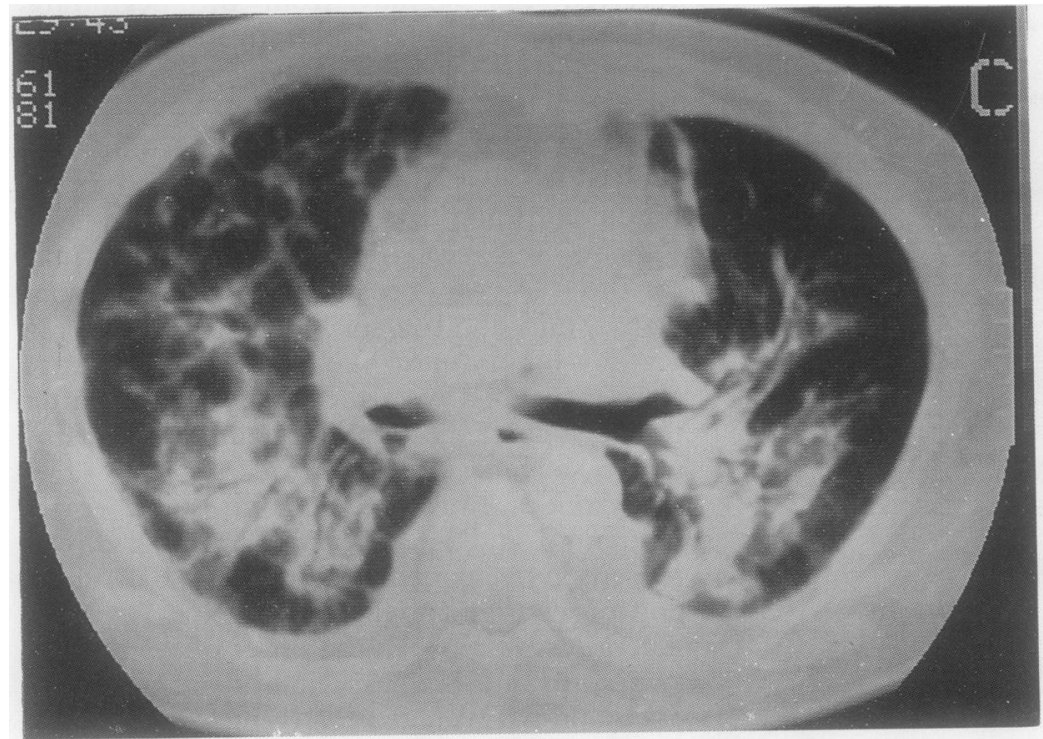

Figure 4 Computed tomogram in nilutamide pneumonitis (patient 8), showing diffuse fluffy opacities with air bronchograms. A pattern of diffuse haze was seen in some patients. levels in blood (4670 kUI/1 (normal < 150)) Serological tests for numerous viral and atypical organisms, fungi, protozoa, and parasites gave negative results in all patients. A test for antinuclear antibodies was carried out in patient 8 , with a negative result.

Alveolar lavage was performed at the time of diagnosis in six patients. Patient 2 was symptom free and refused fibreoptic bronchoscopy, and we thought that patient 4 was too ill to undergo the procedure. Lymphocytosis was present in the lavage fluid from four patients (table 2). In two patients (Nos 6 and 8) the lavage fluid contained a normal percentage of lymphocytes, but neutrophils were increased (table 2). In the four patients with lavage fluid lymphocytosis neutrophils were present in variable proportions, and mild eosinophilia was noted in patients 1 and 3 (table 2). Microbial cultures of sputum or lavage fluid or both gave negative results in all patients. In three patients $(1,6$, and 7$)$ the phenotypic expression of lymphocyte surface markers was examined, and the $\mathrm{CD} 4 / \mathrm{CD} 8$ ratio was found to be low (table 2). Three patients had a repeat lavage after withdrawal of nilutamide. The results are summarised in table 2 .

In three patients $(1,2$, and 6$)$ a leucocyte migration test was performed. Migration was inhibited in two patients ( 1 and 2), with $25 \%$ and $29 \%$ in the presence of 10 and $50 \mu \mathrm{g}$ nilutamide $/ \mathrm{ml}$ in the medium respectively. Leucocyte migration was not inhibited in patient 6.

Transbronchial lung biopsy was performed in patients 5 and 8 (fig 5). It showed interstitial pneumonitis in both, and numerous connective tissue buds in the alveoli of patient 8 . This pattern suggested organising pneumonia. ${ }^{10}$

Outcome was favourable in all patients (table 1), with disappearance of symptoms, and a return to a normal chest radiograph. Resolution occurred within days or weeks after discontinuation of nilutamide in three cases, and more slowly (up to six months) in the other cases (table 1 ). In patient 5 , who did not receive corticosteroids, and in whom nilutamide was reduced from 300 to $150 \mathrm{mg} /$ day, symptoms and the chest radiograph improved slowly over 12 months. Because of the initial severity of their condition prednisolone was given to patients 4 and 8 (40 and $60 \mathrm{mg}$ respectively, tapered over two months). Lung function tests were performed after withdrawal of nilutamide in all patients, and vital capacity improved considerably in six (table 1). Patients 6 and 7 had normal lung function at the time of diagnosis and a mild form of pneumonitis; the results of their lung function tests did not change at follow up.

\section{Discussion}

Causes of drug induced respiratory diseases have substantially expanded during the past 20 years, 140 drugs now being implicated. ${ }^{9}$ An increasing number of distinct clinical pictures also have been described. In addition to the common pattern of interstitial pneumonitis with or without eosinophilia, pulmonary 
Table 2 Bronchoalveolar lavage in patients with nilutamide pneumonits

\begin{tabular}{|c|c|c|c|c|c|c|c|}
\hline $\begin{array}{l}\text { Patient } \\
\text { No }\end{array}$ & $\begin{array}{l}\text { Dates of } \\
\text { lavage }\end{array}$ & $\begin{array}{l}\text { Total } \\
(\text { cells } / \mu l)\end{array}$ & $\begin{array}{l}\text { Lymphocytes } \\
(\%)\end{array}$ & $\begin{array}{l}C D 4 / \\
C D 8\end{array}$ & $\begin{array}{l}\text { Neutrophils } \\
(\%)\end{array}$ & $\begin{array}{l}\text { Eosinophils } \\
(\%)\end{array}$ & $\begin{array}{l}\text { Macrophages } \dagger \\
(\%)\end{array}$ \\
\hline 1 & $\begin{array}{l}\text { d0 } \\
\text { d8 } \\
\text { d21 }\end{array}$ & $\begin{array}{l}480 \\
380 \\
320\end{array}$ & $\begin{array}{l}18 \\
20 \\
25\end{array}$ & $\begin{array}{l}0.40 \\
0.30 \\
0.30\end{array}$ & $\begin{array}{r}25 \\
2 \\
8\end{array}$ & $\begin{array}{r}8 \\
1 \\
-\end{array}$ & $\begin{array}{l}49 \\
78 \\
62\end{array}$ \\
\hline 3 & $\begin{array}{l}\text { d0 } \\
\text { d15 }\end{array}$ & $\begin{array}{l}750 \\
420\end{array}$ & $\begin{array}{l}40 \\
35\end{array}$ & $\begin{array}{l}\text { N.D. }{ }^{\prime} \\
\text { N.D. }\end{array}$ & $\begin{array}{r}10 \\
5\end{array}$ & $\begin{array}{l}15 \\
15\end{array}$ & $\begin{array}{l}30 \\
45\end{array}$ \\
\hline 5 & do & 960 & 62 & N.D. & 1 & 1 & 33 \\
\hline 6 & $\begin{array}{l}\text { d0 } \\
\text { d15 } \\
\text { d30 }\end{array}$ & $\begin{array}{l}900 \\
400 \\
520\end{array}$ & $\begin{array}{r}12 \\
45 \\
3\end{array}$ & $\begin{array}{l}0.10 \\
\text { N.D. } \\
\text { N.D. }\end{array}$ & $\begin{array}{r}50 \\
2 \\
4\end{array}$ & $\begin{array}{l}2 \\
0 \\
1\end{array}$ & $\begin{array}{l}36 \\
53 \\
92\end{array}$ \\
\hline 7 & $\begin{array}{l}\text { d0 } \\
\text { d44 } \\
\text { d145 }\end{array}$ & $\begin{array}{l}150 \\
300 \\
270\end{array}$ & $\begin{array}{r}62 \\
53 \\
9\end{array}$ & $\begin{array}{l}0.50 \\
0.20 \\
0.90\end{array}$ & $\begin{array}{l}3 \\
0 \\
0\end{array}$ & $\begin{array}{l}4 \\
5 \\
0\end{array}$ & $\begin{array}{l}31 \\
42 \\
86\end{array}$ \\
\hline 8 & $\mathrm{~d} 0$ & 150 & 0 & - & 15 & - & 85 \\
\hline
\end{tabular}

^Day (d) 0 is the date of the first lavage.

†Alveolar.

N.D.- not done.

fibrosis, bronchiolitis obliterans with or without organising pneumonia, pleural thickening or effusions, the adult respiratory distress syndrome, bronchial spasm and pulmonary hypertension have been reported..$^{9}$

In our assessment care was taken to exclude other possible causes. Particular attention was directed at ruling out infection, lymphangitic carcinomatosis, and interstitial pneumonitis resulting from exposure to other drugs or airborne contaminants. Culture of lavage fluid and extensive serological testing with possible respiratory pathogens gave negative results. Moreover, five patients had been given antibiotics by their family physician before admission, and this was not followed by any detectable improvement. Although this suggests that infection was not the cause of the respiratory illness in our patients, unusual or fastidiously growing organisms cannot be completely ruled out. Lymphangitic spread from carcinoma of the prostate was also considered, especially as some of these patients had bone metastases at the initial assessment. The clinical course, however, especially the improvement after nilutamide was stopped, excluded this. Two patients had been exposed to asbestos in the distant past, and one of them had asbestosis and pleural plaques. The relatively acute and reversible chest symptoms are unlikely to be related to the prior exposure to asbestos. Likewise, exposure to birds in the case of patient 3 is not relevant, as he did not improve until nilutamide was withdrawn. Congestive heart failure was considered in patient 4 on the basis of prior evidence of coronary heart disease. This hypothesis, however, was dismissed in the light of the clinical and echographic evaluation and of the lack of effect of diuretics.

Patient 3 was receiving pindolol in addition to nilutamide, and some $\beta$ blockers are known to induce respiratory problems. ${ }^{10}$ In fact, pindolol has been implicated in two cases of pleuropulmonary side effects. ${ }^{112}$ In one the patient developed drug induced lupus, with bilateral pleural effusions and positive antinuclear antibodies. ${ }^{11}$ The other presented with progressive dyspnoea, and open lung biopsy showed "pulmonary fibrosis." 12 In any event, pindolol was continued in our patient after nilutamide was withdrawn, and the pulmonary infiltrates cleared. The drug history in patient 8 was more complex. He was taking flecainide and enalapril in addition to nilutamide, and interstitial pneumonitis with lavage fluid lymphocytosis has been described in patients exposed to flecainide ${ }^{1314}$ and also to angiotensin converting enzyme inhibitors. ${ }^{15}$ Nevertheless, (as in patient 3 ) these drugs were continued while nilutamide was stopped, and the pulmonary shadowing cleared. Finally, the possible role of triptoreline needs to be evaluated, inasmuch as polymyositis with interstitial pneumonitis has been recently reported after injection of the luteinising hormone releasing hormone analogue leuprolide. ${ }^{16}$ In the five patients of the present series who were having it triptoreline was continued while nilutamide was stopped, and the chest radiograph became normal.

Nilutamide pneumonitis developed after administration of 3-38 $\mathrm{g}$ of the drug over periods of 10-225 days. Patient 1 received the lowest reported dose associated with pulmonary side effects, whereas the doses received by the other patients fall into the range mentioned in previous reports..$^{3-5}$ Although discontinuation of nilutamide was followed by considerable improvement, complete healing with a return to normal of lung volumes and chest radiograph was completed only after six to 12 months.

The cell profile of the lavage fluid was notable for increased lymphocytes in four out of six patients. Earlier reports also mentioned lymphocytic alveolitis in nilutamide pneumonitis, ${ }^{3-5}$ similar to pneumonitis due to gold salts, $\beta$ blockers, and methotrexate. ${ }^{9}$ Repeat lavage in three patients showed that total cells or lymphocytes, or both, had decreased after the discontinuation of nilutamide. Lymphocytes were still increased, however, in patient 6 at the second lavage, even though nilutamide had been stopped two weeks earlier. This patient was not taking corticosteroids. Patient 8 had 

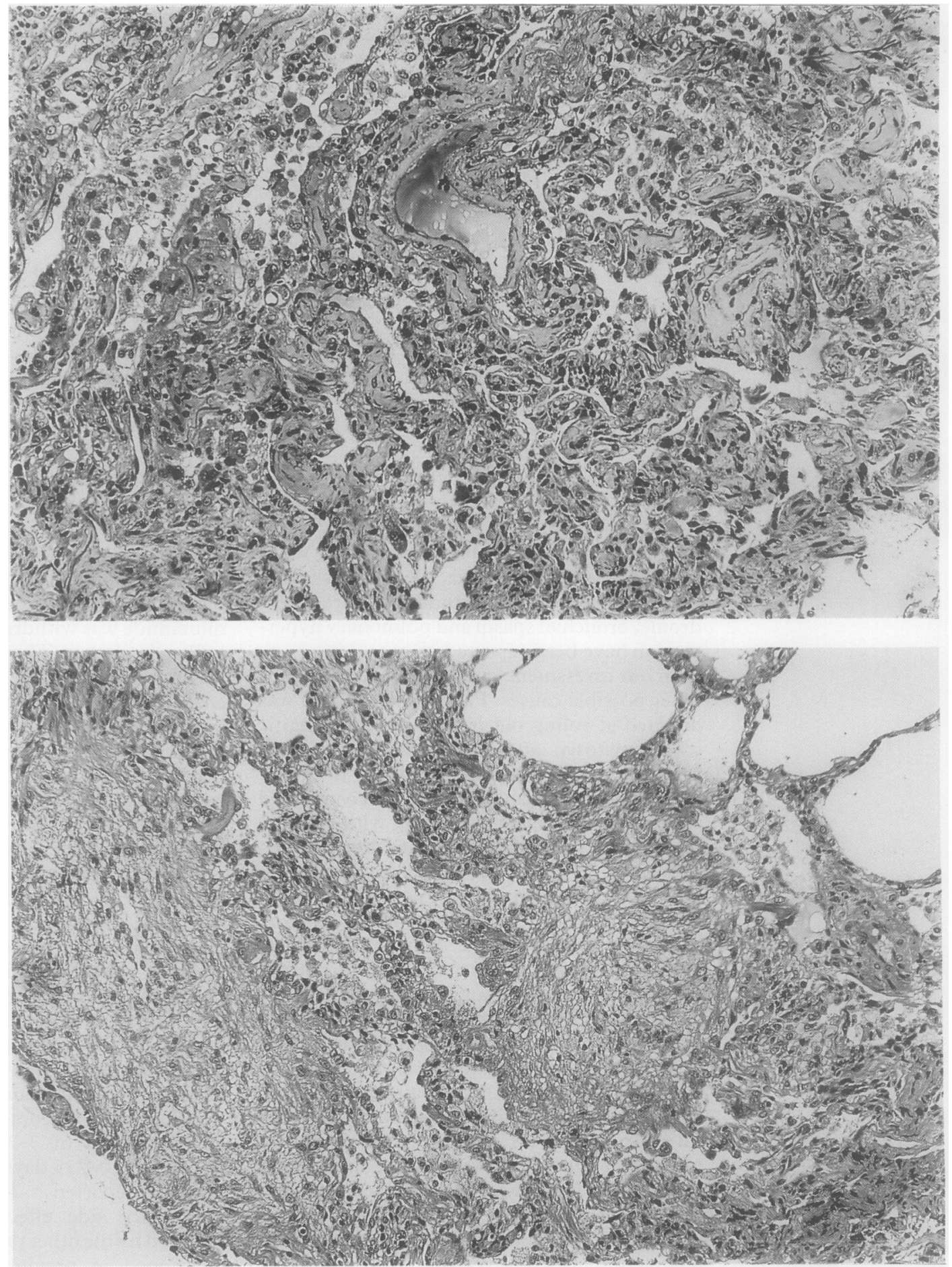

Figure 5 Transbronchial lung biopsy specimens from patients 5 (top) and 8 (bottom). Widening of alveolar septa by connective tissue and mild mononuclear infiltrates are present in both specimens. In addition, numerous buds of connective tissue ("bourgeons conjonctifs") consistent with organising pneumonia were seen in the specimen from patient 8 (Masson's trichrome stain).

pulmonary infiltrates with peripheral eosinophilia, but his lavage fluid smear did not show eosinophils. The results of lavage may be flawed in this patient, however, owing to the limited amount of fluid instilled (see under "Methods").

We cannot comment exhaustively on the histological picture of nilutamide pneumonitis, as a specimen of lung tissue was available in only two cases. One showed the histological pattern of organising pneumonia, as already described after exposure to such drugs as amiodarone, $\beta$ blockers, bleomycin, gold, and sulphasalasopyridine. ${ }^{10}$

A recent report described rechallenge of a patient with nilutamide, which led to recurrence of the pneumonitis. ${ }^{5}$ Nilutamide was continued at a reduced dosage in one of our patients, but this did not prevent him from recovering, and similar observations have been made for amiodarone. ${ }^{17} 18$

It is difficult to estimate the exact frequency 
of nilutamide pneumonitis. Prospective controlled clinical trials, as well as files from the department of drug safety at Roussel Uclaf, estimate the incidence of amiodarone pneumonitis at $1-2 \%$. Among the 41 cases of drug induced pneumonitis seen at our institution during the past 11 years, nilutamide lung ranked second only to amiodarone pneumonitis, of which we have seen 15 cases.

In summary, patients taking nilutamide may develop interstitial pneumonitis with fever, hypoxaemia, bilateral pulmonary infiltrates, and lymphocytosis in the lavage fluid. The severity ranges from minimal to severe, but the prognosis after withdrawal of the drug is good.

\section{Addendum}

A recent report by Gomez et al ${ }^{19}$ described a 69 year old patient with carcinoma of the prostate who was treated by a luteinising hormone releasing hormone analogue and nilutamide $200 \mathrm{mg}$ daily. After two months of treatment with nilutamide (total dose $12.2 \mathrm{~g}$ ) he developed respiratory symptoms, bibasilar opacities on the chest radiograph, hypoxaemia $\left(\mathrm{PaO}_{2} 8.6 \mathrm{kPa}\right)$, and deranged liver function. Bronchoalveolar lavage showed increased lymphocytes (52\%; CD4/CD8 ratio not given). Interstitial pneumonitis was found by histological examination (open lung biopsy). Improvement followed cessation of nilutamide, results of pulmonary function tests improved within three months, and liver function returned to normal. Follow up bronchoalveolar lavage was not performed. The antiandrogen flutamide was then given with no adverse effect.

The case reported by Gomez et al resembles those we describe regarding duration of treatment and clinical and radiographic presentation. This indicates that nilutamide pneumonitis has a relatively homogeneous pattern. Accordingly, we believe that clinical history, bronchoalveolar lavage and transbronchial biopsy may reliably establish the diagnosis of nilutamide pneumonitis in most cases, and that open lung biopsy should remain the exception.

We are indebted to Dr Laurent Brondel and to Professor Paule Marie Carli and her staff for their valuable help. We thank Drs Abbey, I Balvet, P Fargeot, JH Gasse, F Robin, F Tourmente, and $D$ Yeme for referring patients or communication of pathology material. Thanks are due to Anne Breluque and Philippe Mathiot for conducting the marketing survey. The secretarial skills of Patricia Bey and Nicole Beauruel are gratefully acknowledged. Funds from La Faculté de Médecine de Dijon et l'Université de Bourgogne, Le Fonds de Lutte contre les Maladies Respiratoires (Grant 89-MR 11), Astra-France, Bristol-Myers, Glaxo, Euthérapie, and Smith-Kline-Beecham enabled us to acquire the photomicrographic equipment used in this study. The kind support from Roussel Uclaf is gratefully acknowledged.

1 Beland G, Elhilali M, Fradet Y, Laroche B, Ramsey EW, Trachtenberg J, et al. Total androgen ablation: Canadian experience. Urol Clin North Am 1991;18:75-82.

2 Decensi A, Guarneri D, Paoletti MC, Lalanne JM, Merlo F, Boccardo F. Phase II study of the pure nonsteroidal antiandrogen nilutamide in prostatic cancer. Eur $J$ Cancer 1991;27:1100-4.

3 Seigneur J, Trechot P, Hubert J, Lamy P. Pulmonary complications of hormone treatment in prostate carcinoma [letter]. Chest 1988;93:1106.

4 Ode P, Guy C, Rousse TH, Ollagnier M, Guerin JC. Pneumopathie interstitielle d'origine medicamenteuse: le nilutamide (Anandron) [abstract]. Rev Mal Respir 1988;5:R137.

5 Akoun GM, Liote HA, Liote F, Gauthier-Rahman S, Kuntz D. Provocation test coupled with bronchoalveolar lavage in diagnosis of drug (nilutamide)-induced hypersensitivity pneumonitis. Chest 1990;97:495-8.

6 Quanjer $\mathrm{Ph}$. Standardization of lung function testing. Bull Eur Physiopathol Respir 1983;19(suppl 5):7-10.

7 Miller A, Thornton JC, Warshaw R, Anderson H, Teirstein AS, Selikoff IJ. Single-breath diffusing capacity in a representative sample of the population of Michigan, a large industrial state. Am Rev Respir Dis 1983;127:270-7.

8 Laviolette $M$. Lymphocyte fluctuation in bronchoalveolar fluid in normal volunteers. Thorax 1985;40:651-6.

9 Cooper JAD, White DA, Matthay RA. Drug-induced pulmonary disease, I: Cytotoxic drugs. II: Noncytotoxic drugs. Am Rev Respir Dis 1986;133:321-40, 488-505.

10 Camus Ph, Lombard JN, Perrichon M, Piard F, Guérin JC, Bejui-Thivolet $F$, et al. Bronchiolitis obliterans organising pneumonia in patients taking acebutolol or amiodarone. Thorax 1989;44:711-5.

11 Bensaid J, Aldigier JC, Gualde N. Systemic lupus erythematosus syndrome induced by pindolol. $B M J$ 1979;i: $1603-4$.

12 Musk AW, Pollard JA. Pindolol and pulmonary fibrosis. BMJ 1979; ii:581-2.

13 Akoun GM, Cadranel JL, Israel Biet D, Gauthier Rahman S. Flecainide-associated pneumonitis. Lancet 1991; 337:49.

14 Hanson H, Evrard P, Mahieu P, Wallamacq P, Friob M, Hassoun A. Flecainide-associated interstitial pneumonitis. Lancet 1991;337:371-2.

15 Schatz PL, Mesologites D, Hyun J, Smith W, Lahiri B. Captopril-induced hypersensitivity lung disease. Chest 1989;95:685-7.

16 Crayton H, Bohlman T, Sufit R, Graziano FM. Druginduced polymyositis secondary to leuprolide acetate (Lupron) therapy for prostate carcinoma. Clin Exp Rheumatol 1991;9:525-8.

17 Leech JA, Gallastegui PJ, Swiryn S. Pulmonary toxicity of amiodarone. Chest 1984;85:444-5.

18 Lok-Wan Liu F, Cohen RD, Downar E, Butany JW, Edelson JD, Rebuck AS. Amiodarone pulmonary toxicity. Functional and ultrastructural evaluation. Thorax 1986; 41:100-5.

19 Gomez JL, Dupont A, Cusan L, Tremblay M, Labrie F. Simultaneous liver and lung toxicity related to the nonsteroidal antiandrogen nilutamide (Anandron): a case report. Am J Med 1992;92:563-6. 